\title{
Barreiras de acessibilidade enfrentadas por pessoas surdas no setor de serviços: uma revisão integrativa da literatura
}

\author{
Monica Holdorf ${ }^{1}$ \\ Wilson Robinson ${ }^{2}$
}

\begin{abstract}
Resumo: A acessibilidade é um direito de todo o cidadão. Para muitas pessoas surdas, o acesso às atividades existentes na sociedade é garantido quando há a possibilidade de comunicação em LS. O objetivo deste estudo foi identificar os problemas de acessibilidade enfrentados pelas pessoas surdas no setor de serviços. Para tanto, foi realizada uma revisão integrativa da literatura, a partir dos termos: deaf; "hard of hearing"; "hearing impaired"; access; inclusion; communication. Os serviços encontrados foram organizados em quatro categorias: saúde, emergência, sistema de justiça e cultura. Constatou-se que, independentemente da situação econômica do país, todos os estudos apontaram a existência de barreiras atitudinais ou comunicacionais, tais como: a falta de conscientização das organizações a respeito das necessidades e singularidades do público surdo, a rara presença de intérpretes de LS, ou profissionais capacitados, bem como a ausência de informações sobre os serviços em LS. Com a ausência de recursos de comunicação, os surdos se deparam com três situações: (1) precisam do auxílio de um familiar ou conhecido e assim perdem sua autonomia; (2) utilizam a escrita, ou a leitura orofacial (linguagens estas que nem todos os surdos têm domínio ou facilidade) e correm o risco de não compreenderem as informações corretamente; e (3) evitam ou desistem de acessar o serviço.

Palavras-chave: Acessibilidade; Pessoas surdas; Deficientes auditivos; Surdez; Serviços.

\section{Accessibility Barriers Faced by Deaf People in the Service Sector: An} Integrative Literature Review
\end{abstract}

\begin{abstract}
Accessibility is a right of every citizen. For deaf people, users of sign language (SL), access to existing activities in society is guaranteed when there is the possibility of communication in SL. The objective of this study was to identify the accessibility problems faced by deaf people in the service sector. Therefore, an integrative review of the literature was carried out using the terms deaf, "hard of hearing", "hearing impaired", access, inclusion and communication. The services found were organized into four categories: health, culture, emergencies and public buildings. It was found that regardless of the country (either developing or developed), all studies pointed to the existence of communicational barriers. Among them, we have: the lack of awareness of the organizations regarding the needs and singularities of the deaf public, the rare
\end{abstract}

\footnotetext{
${ }^{1}$ Doutoranda do Departamento de Engenharia de Produção e Sistemas, UFSC. Mestre em Engenharia de Produção na área de Ergonomia. Designer. Florianópolis, Santa Catarina. mnikalopez@gmail.com.

${ }^{2}$ Mestre em Música. Licenciado em Música, especialista em Educação Inclusiva e em Gestão Cultural. Professor de Música e Educação Especial na UERGS. wilsonxinho@yahoo.com.br.
} 
presence of interpreters of SL, or trained professionals, as well as the lack of information about the services in SL. With the lack of communication resources, the deaf face three situations: (1) they need help from a relative or acquaintance and thus lose their autonomy; (2) use writing, or orofacial reading (not all deaf people master these languages or find it easy to use them) and run the risk of not understanding the information correctly; (3) avoid or give up accessing the service.

Keywords: Accessibility; Access; Deaf people; Hard of hearing; Deafness; Services.

Barreras de accesibilidad que enfrentan las personas sordas en el sector de servicios: Una Revisión integradora

Resumen: La accesibilidad es un derecho de todos los ciudadanos. Para las personas sordas, usuaria de la lengua de signos (LS), el acceso a las actividades existentes en la sociedad está garantizado cuando existe la posibilidad de comunicación en LS. El objetivo de este estudio fue identificar los problemas de accesibilidad que enfrentan las personas sordas en el sector servicios. Por lo tanto, se realizó una revisión integradora de la literatura, utilizando los términos: deaf, "hard of hearing", "hearing impaired", access, inclusión y comunicación. Se constató que independientemente del país, sea él de primer o tercer mundo, todos los estudios apuntaron la existencia de barreras actitudinales o comunicacionales, como la falta de concientización de las organizaciones respecto a las necesidades y singularidades del público sordo, la rara presencia de intérpretes de LS, o profesionales capacitados, así como la ausencia de información sobre los servicios en LS. Con la ausencia de recursos de comunicación, los sordos se enfrentan a tres situaciones: (1) requerir la ayuda de un familiar o conocido y así pierden su autonomía; (2) utilizan la escritura, o la lectura orofacial (no todos los sordos saben utilizar tales recursos) y correr el riesgo de no comprender la información correctamente; (3) evitan o desisten de acceder al servicio.

Palabras clave: Accesibilidad; Acceso; Personas sordas; Personas con discapacidad auditiva; Sordera; Servicios.

\section{Introdução}

A acessibilidade é um direito e um meio de assegurar que as pessoas com deficiência, ou mobilidade reduzida, sejam capazes de exercer todos os direitos e liberdades fundamentais e possam participar plenamente da sociedade com igualdade de condições. Para que isso ocorra, os Estados devem tomar medidas apropriadas para assegurar o acesso ao ambiente físico, ao transporte, à informação e às comunicações - incluindo tecnologias e sistemas de informação e comunicação - e outras instalações de serviços públicos ou privados de uso público. Tais medidas devem incluir a identificação e a eliminação de barreiras à acessibilidade (BRASIL, 2015; UNITED NATIONS, 2015).

O conceito de acessibilidade é usualmente associado a barreiras físicas e arquitetônicas, entretanto, é um conceito muito amplo e que pode ser 
observado por diferentes perspectivas, assumindo, portanto, várias modalidades. Por este prisma, Sassaki (2006, p.68) compreende que o acesso deve ser garantido, a todas as pessoas, em seis diferentes dimensões: (i) arquitetônica: eliminar barreiras físicas; (ii) comunicacional: não deve haver barreiras na comunicação entre as pessoas; (iii) metodológica: os métodos de lazer, trabalho e educação devem ser livres de barreiras; (iv) instrumental: eliminar barreiras para que todos possam utilizar ferramentas, utensílios etc.; (v) programática: não deve haver barreiras embutidas em políticas públicas, legislações, normas etc.; (vi) atitudinal: sem preconceitos, estereótipos, estigmas e discriminações nos comportamentos da sociedade para pessoas que têm deficiência.

A população surda e deficiente auditiva (DA) vivencia diariamente barreiras comunicacionais para acessar todo tipo de serviços e atividades que envolvem a interação com pessoas ouvintes, seja por meio de linguagem oral ou escrita. Assistir a um filme, ler as informações na internet, ir ao teatro, à farmácia, ao banco ou ao hospital são atividades corriqueiras para a maioria das pessoas, mas para os surdos/DA são repletas de barreiras ou até mesmo inacessíveis, tornando-os dependentes de uma pessoa ouvinte.

As dificuldades comunicativas podem ser maiores ou menores devido a diversos fatores, como: o grau de desenvolvimento da linguagem (oral); o grau da perda auditiva e do período no qual ela ocorreu (antes ou depois da aquisição da linguagem oral); e da educação, histórico, ou idioma principal da pessoa surda (CHAVEIRO et al., 2008; BARNETT, 2002). Barnett (2002) e Chaveiro et al. (2008) classificam as dificuldades comunicativas em três categorias: (1) pessoas com deficiência auditiva: são aquelas com perda auditiva e que ainda podem se beneficiar do código verbal e se comunicar por meio dele; (2) pessoas surdas que se comunicam oralmente: são pessoas com surdez profunda ou severa que tiveram algum contato com a linguagem oral, ou seja, surdos que receberam educação oral (surdos oralizados), ou que perderam a audição após a aquisição da linguagem oral; (3) surdos que se comunicam em língua de sinais: são aqueles que não tiveram contato com a linguagem oral (perderam a audição antes dos três anos - surdos pré-linguais). Eles têm como primeira língua (L1), a língua de sinais (LS). Muitos surdos bilíngues também se enquadram nesta categoria, nasceram surdos, têm como L1 a língua de sinais, mas conseguem estabelecer comunicação por meio da escrita e leitura labial.

Independentemente da situação linguística da pessoa surda ou DA, é preciso conhecer suas necessidades, características e dificuldades para proporcionar acessibilidade nas mais diversas esferas sociais. Para muitos surdos, especialmente os pré-linguais, a forma de 
comunicação mais eficaz é a língua de sinais (CROWE, 2017; BARNETT, 2002). As pessoas que nunca tiveram contato com o som possuem uma forma diferente de perceber o mundo e a linguagem, percebendo-os por meio da visão e das mudanças sensoriais no ambiente (STROBEL, 2008). A LS, por ser de expressão visual-motora, proporciona ao surdo o desenvolvimento do pensamento e da linguagem de forma compatível com sua percepção de mundo. A LS é um sistema linguístico lídimo e de aquisição natural pela população surda, possuindo estrutura gramatical independente das línguas orais (AZEREDO et al., 2006). Ela não é uma língua universal, cada país, ou até mesmo região, possui a sua. No Brasil, a LS oficial, desde 2002, é a Língua Brasileira de Sinais - Libras (STROBEL, 2008; BRASIL, 2002).

Após séculos de luta da comunidade surda, foram criadas leis para que os surdos tivessem seus direitos assegurados nos mais diversos setores da sociedade. Dentre eles, encontra-se o setor de serviços públicos e concessionárias de serviços públicos. No Brasil, foi estabelecido que os serviços públicos devem oferecer atendimento em Libras, e os recursos de comunicação necessários para atender esta população de forma equitativa (BRASIL, 2005). No mundo também existem diversas Leis, como a do Brasil, que estão em consonância com a "Convention on the Rights of Persons with Disabilities", e estabelecem medidas para o atendimento da população surda - em língua de sinais; como, por exemplo, o "The Americans with Disabilities Act", dos Estados Unidos (UNITED NATIONS, 2015).

Serviço pode ser definido como o "resultado gerado por atividades na interface entre 'fornecedor e cliente' e por atividades internas do fornecedor para atender às necessidades do cliente" (PALADINI 2005, p. 332 apud NBR ISO9004-2). Satisfazer as necessidades do cliente é um dos principais objetivos dos sistemas de prestação de serviço (MONT, 2010). Dependendo da característica deste serviço, o grau de contato com o cliente é maior ou menor, assim como sua customização (SILVESTRO, 1999). Quanto maior o grau de contato com o cliente surdo, mais complexa se torna a comunicação, e maior é a exigência de conhecimento e competências requeridas dos profissionais e organizações em relação à língua e à Cultura Surda. Diante do exposto, levantam-se as seguintes perguntas de pesquisa: Qual o panorama da acessibilidade aos surdos e DA no setor de serviços a nível mundial? Quais as barreiras que eles enfrentam para acessá-los? Este estudo teve como objetivo identificar os problemas de acessibilidade enfrentados pelas pessoas surdas e DA no setor de serviços - nos âmbitos nacional e internacional. 


\section{Método}

Para atingir o objetivo proposto neste artigo, utilizou-se como método a revisão integrativa da literatura. Este foi escolhido pois permite levantar estudos de diferentes métodos de pesquisa e que fornecem uma variedade de perspectivas e uma compreensão mais abrangente do fenômeno em estudo (WHITTEMORE; KNAFL, 2005). Essa revisão seguiu as seis etapas indicadas pelo modelo de Botelho e Cunha (2011), conforme Imagem 1.

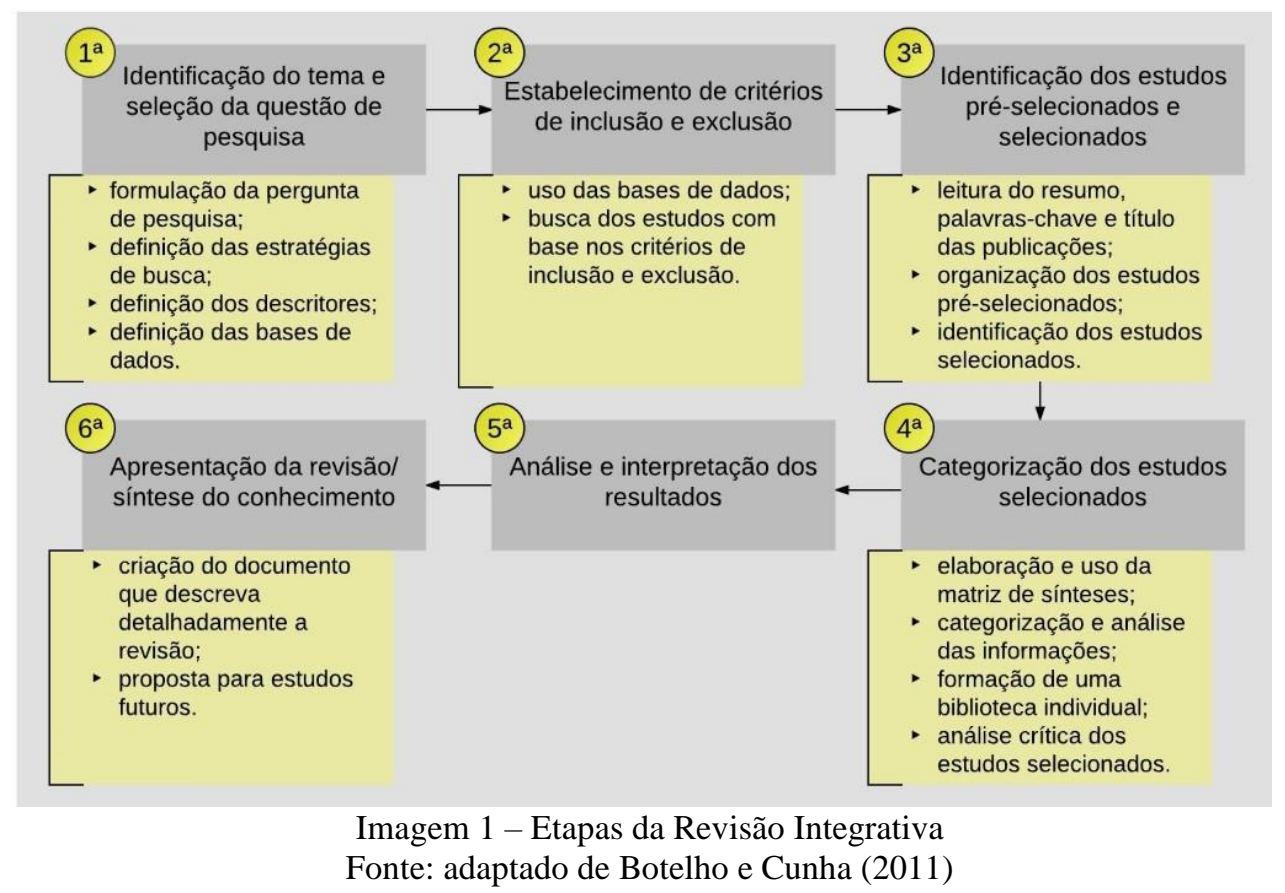

A identificação do tema e a questão de pesquisa foram relatadas na introdução. $\mathrm{O}$ próximo passo foi definir os critérios de inclusão e exclusão e os critérios de busca. Os estudos incluídos devem ser: realizados com pessoas surdas usuárias da LS ou sobre pessoas surdas usuárias da LS; pesquisas oriundas de periódicos científicos com dados primários ou com dados secundários que revelam as barreiras de acessibilidade daquele determinado serviço; bem como artigos com os seguintes filtros: idioma (português, inglês e espanhol) e ano de publicação (2007 a 2019). Os estudos devem ser excluídos se: a amostra não contiver número significativo de pessoas surdas (como amostras que contêm diversos tipos de deficiência, ou artigos com surdo-cegos - pois estes possuem necessidades diferentes dos surdos); artigos teóricos; pesquisas que não estejam disponíveis para download ou sistema de comuta; e serviços de educação ou de dimensão metodológica (optou-se por analisar serviços de média e baixa customização e contato com o cliente, que são a maioria, pois os 
serviços de educação possuem características distintas dos demais e são amplamente explorados em pesquisas científicas).

$\mathrm{Na}$ sequência, foram definidos os descritores e truncamentos. Para ser possível levantar pesquisas de diversas áreas, os descritores selecionados são generalistas; logo, foi realizado o seguinte truncamento: (deaf* OR "hard of hearing" OR "hearing impaired") AND (access $*$ OR inclusion OR communication) NOT (deafblind* OR cochlear OR newborn OR child* OR audio* OR gene* OR school OR education). Para as buscas foi estabelecido como critério que as bases de dados devem constar na lista de periódicos da Coordenação de Aperfeiçoamento de Pessoal de Nível Superior (CAPES).

Foram selecionadas as bases: Scopus, Web of Science e Ebsco Discovery e SciElo. Após a busca nas bases de dados, os artigos foram exportados para o software End NoteWeb, onde foram retirados os estudos duplicados e deu-se início à etapa de filtragem das pesquisas, a qual foi realizada na seguinte sequência: (1) leitura do título; (2) leitura do resumo; (3) leitura integral da pesquisa; e (4) seleção do portfólio final. Em seguida foram realizadas a tabulação e a análise de dados. A discussão foi elaborada a partir da técnica de análise de conteúdo temática (BARDIN, 1977).

\section{Resultados}

As buscas nas bases de dados foram realizadas em janeiro de 2019 - foram levantados 2056 artigos. Ao aplicar os filtros foram encontrados os seguintes resultados: (1) leitura títulos, 1027 artigos; (2) leitura resumos, 337 artigos; (3) leitura integral e portfólio final, 20 artigos. A partir da leitura das pesquisas foram identificados quatro tipos de serviço, bem como o número de artigos pertencente a cada um deles: serviços de saúde $(n=10)$; situações de emergência e catástrofe $(n=3)$; serviços do sistema de justiça $(n=4)$; e serviços de cultura $(n=3)$. Os países com o maior número de publicações foram os Estados Unidos, seguido do Brasil e do Reino Unido. Os Estados Unidos foram o único país que teve pesquisas nas quatro categorias de serviços. Outros dados bibliométricos, como número de publicação por ano e por país, podem ser observadas na Imagem 2. 


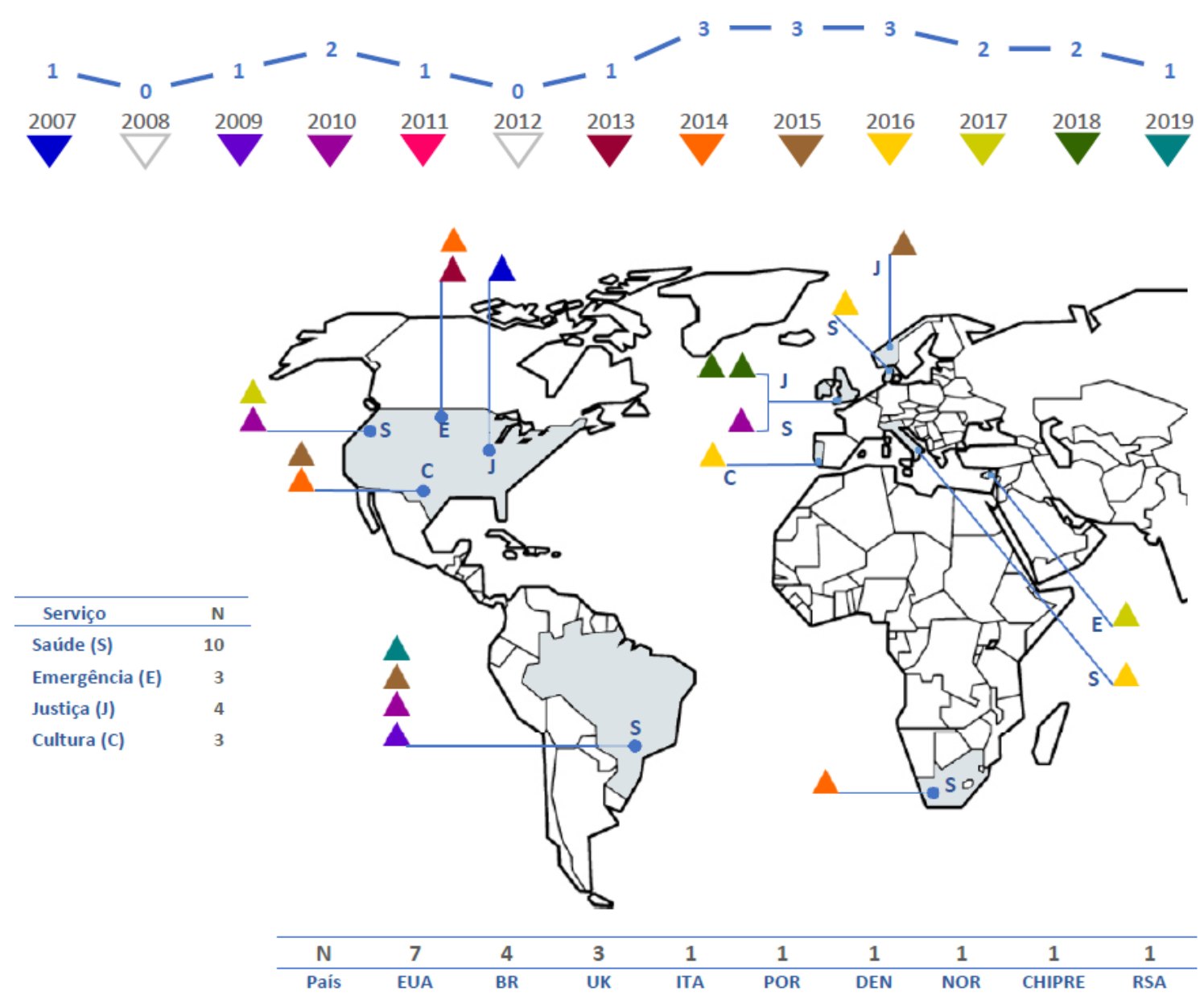

Imagem 2 - Dados bibliométricos da revisão integrativa da literatura Fonte: própria.

Os itens a seguir trazem informações detalhadas sobre cada pesquisa de acordo com a categoria de serviço a qual ela pertence.

\subsection{Acessibilidade aos Serviços de Saúde}

Os dez estudos abordam diversos temas relacionados ao acesso e à utilização dos serviços de saúde. Dentre eles, estão: a falta de preparo dos profissionais da saúde para atender um paciente surdo e suas consequências; a falta de intérpretes de LS e os problemas relacionados a este serviço; a falta de acesso aos serviços e informações relativas à prevenção de doenças; e as preferências comunicacionais das pessoas surdas. Quatro estudos revelam que os profissionais de saúde não estão preparados para atender ao público surdo/DA, pois não sabem como se portar diante de uma pessoa surda, não conhecem as diferentes formas de comunicação utilizadas por essa população - especialmente a LS e conhecimentos gerais 
sobre a Cultura Surda (SANTOS; PORTES, 2019; PENDERGRASS et al., 2017; SIRCH et al., 2016; SKØТ, 2016).

Cinco estudos apontaram falta, ausência ou dificuldade de acesso a intérpretes de LS, o que seria um facilitador para o atendimento com segurança de informação aos surdos (SANTOS; PORTES, 2019; PENDERGRASS et al., 2017; SKØT, 2016; KRITZINGER et al., 2014; PEREIRA; CARVALHO, 2010). Esses estudos identificaram também que os profissionais de saúde não são treinados para trabalhar com um intérprete (SIRCH et al., 2016; SKØT, 2016; OLIVEIRA et al., 2015; KRITZINGER et al., 2014; PEREIRA; CARVALHO, 2010) - durante a consulta, eles estabelecem comunicação diretamente com o intérprete ou com o acompanhante, privando o surdo de participar e compreender o seu processo de saúde-doença. Esta situação, ligada à necessidade da presença de um interlocutor, leva o surdo à perda de sua privacidade, individualidade e independência. Muitos sentem-se constrangidos ao compartilhar informações pessoais com uma terceira pessoa (SANTOS; PORTES, 2019; SIRCH et al., 2016; OLIVEIRA et al., 2015).

Os surdos esperam participar da gestão de sua própria saúde, receber e compreender as informações relativas ao seu tratamento (SIRCH et al., 2016). Três estudos evidenciaram que os surdos sentem indignação, raiva, decepção ou frustração por não serem compreendidos ou por não compreenderem os profissionais da saúde, muitas vezes deixando o consultório sem compreender o diagnóstico ou as orientações sobre seu tratamento (SANTOS; PORTES, 2019; KRITZINGER et al., 2014; PEREIRA; CARVALHO, 2010). Muitos sentem medo de fazer uma pergunta simples, de falar algo errado e serem inferiorizados por sua falta de conhecimento em saúde (KRITZINGER et al., 2014; PEREIRA; CARVALHO, 2010). Tais fatores podem levar o surdo à dependência de um acompanhante, e/ou ao adiamento ou desistência de procurar um serviço de saúde (SANTOS-PORTES, 2019; PEREIRA; CARVALHO, 2010). Dentro deste contexto, o estudo de Freire et al. (2009) averiguou que a população surda/DA possui maior prevalência em consultas em hospitais em outras cidades do que os ouvintes, e, 2,1 vezes mais prevalência de internação hospitalar no ano anterior. Tais dados podem refletir a dificuldade de acesso a serviços ambulatoriais pelos D.A, podendo levar à procura do nível terciário, assim como a dificuldade de alcançar essa população com medidas preventivas. As informações detalhadas sobre as pesquisas estão localizadas no Quadro 1. 


\begin{tabular}{|c|c|c|c|}
\hline Ref./ País & Objetivo & $\begin{array}{l}\text { Caracterização da Pesquisa/ } \\
\text { Dados da amostra }\end{array}$ & Principais Resultados e Constatações \\
\hline $\begin{array}{l}\text { Santos- } \\
\text { Portes } \\
\text { (2019) } \\
\text { Brasil }\end{array}$ & $\begin{array}{l}\text { Analisar as } \\
\text { percepções de } \\
\text { indivíduos com } \\
\text { surdez em relação ao } \\
\text { processo } \\
\text { comunicacional com } \\
\text { profissionais de saúde } \\
\text { da Atenção Básica do } \\
\text { Estado do Rio de } \\
\text { Janeiro. }\end{array}$ & $\begin{array}{l}\text { Abordagem: qualitativa. } \\
\text { Objetivo: descritivo e analítico. } \\
\text { P.T.: questionário. } \\
\text { Tipo de dados: primários. } \\
\text { n= } 121 \text { surdos. } \\
\text { Local: Estado do Rio de Janeiro. }\end{array}$ & $\begin{array}{l}\text { - Profissionais de saúde despreparados: } 83 \% \text { dos surdos disseram } \\
\text { nunca terem sido atendidos por profissionais da saúde que } \\
\text { dominassem a Libras; } 61 \% \text { dos surdos disseram que não são } \\
\text { compreendidos se não estiverem acompanhados de um ouvinte; } 82 \% \\
\text { dos surdos declaram não compreender o diagnóstico; } 70 \% \text { não } \\
\text { compreendem as orientações sobre seu tratamento a partir das } \\
\text { estratégias de comunicação utilizadas pelos médicos (escrita - leitura } \\
\text { labial, mímica); e } 66 \% \text { sentem-se inseguros após o encontro clínico } \\
\text { quanto ao diagnóstico e tratamento repassados. } \\
\text { - A ausência de um mediador (intérprete ou acompanhante) é } \\
\text { responsável pela desistência de } 63 \% \text { dos surdos em buscar as } \\
\text { unidades de saúde. }\end{array}$ \\
\hline $\begin{array}{l}\text { Pendergrass } \\
\text { et al. (2017) } \\
\text { Estados } \\
\text { Unidos }\end{array}$ & $\begin{array}{l}\text { Examinar as } \\
\text { percepções de } \\
\text { profissionais de } \\
\text { enfermagem sobre } \\
\text { barreiras e } \\
\text { facilitadores na } \\
\text { prestação de cuidados } \\
\text { de saúde para usuários } \\
\text { de ASL surdos. }\end{array}$ & $\begin{array}{l}\text { Abordagem: qualitativa. } \\
\text { Objetivo: descritiva. } \\
\text { P.T.: entrevista semiestruturada. } \\
\text { Tipo de dados: primários. } \\
\mathrm{n}=10 \text { profissionais de } \\
\text { enfermagem credenciados. } \\
\text { Local: Mississippi (EUA). } \\
\text { Obs.: Modelo socioecológico. }\end{array}$ & $\begin{array}{l}\text { - A maioria dos profissionais de enfermagem fez poucos } \\
\text { atendimentos a pessoas surdas durante suas carreiras. Eles sabem } \\
\text { pouco ou nada de ASL (Língua Americana de Sinais), mas gostariam } \\
\text { de aprender. A comunicação acaba sendo realizada por meio da } \\
\text { escrita e leitura orofacial. Há também a ausência de intérpretes de } \\
\text { LS. Todos relataram se sentir mais seguros na sua presença. } \\
\text { - Os profissionais não têm conhecimento sobre de quem é a } \\
\text { responsabilidade da contratação do intérprete; não há um protocolo } \\
\text { sobre o atendimento ao surdo/DA - consequentemente, não há um } \\
\text { aviso prévio da necessidade deste profissional. } \\
\text { - Há falta de conscientização dos profissionais quanto à legislação } \\
\text { referente ao fornecimento e pagamento de intérpretes. Para os } \\
\text { participantes só é importante solicitar um intérprete quando nenhum } \\
\text { outro método de comunicação for possível, ou em situação de risco } \\
\text { de vida, demonstrando a falta de consciência sobre a importância da } \\
\text { LS para a comunicação segura e eficaz com os surdos. }\end{array}$ \\
\hline Skøt (2016) & $\begin{array}{l}\text { Explorar as barreiras } \\
\text { enfrentadas pelos } \\
\text { indivíduos surdos e } \\
\text { com deficiência } \\
\text { auditiva na } \\
\text { Dinamarca ao acessar } \\
\text { serviços médicos e } \\
\text { psicossociais após } \\
\text { desastres em larga } \\
\text { escala ou experiências } \\
\text { traumáticas } \\
\text { individuais. }\end{array}$ & $\begin{array}{l}\text { Abordagem: qualitativa. } \\
\text { Objetivo: estudo descritivo. } \\
\text { P.T.: entrevista semiestruturada } \\
\text { Tipo de dados: primários. } \\
\text { n= } 9 \text { surdos ( } 6 \text { pessoas surdas e } 3 \\
\text { deficientes auditivas que } \\
\text { vivenciaram pelo menos } 1 \text { evento } \\
\text { traumático, ou desastre). } \\
\text { Sexo: } 1 / 4 \text { feminino. } \\
\text { Idade: de } 27 \text { a } 81 \text { anos. }\end{array}$ & $\begin{array}{l}\text { - Existem falhas significativas no acesso e provisão dos serviços de } \\
\text { saúde e serviços psicossociais em situações pós-desastre para pessoas } \\
\text { surdas ou DA. } \\
\text { - Quanto às questões relacionadas aos serviços de saúde foi } \\
\text { constatado que: há falta de conhecimento sobre LS, características e } \\
\text { peculiares das pessoas surdas pelos atendentes e profissionais da } \\
\text { saúde, bem como falta de sensibilidade em buscar formas alternativas } \\
\text { de comunicação; existem também problemas de acesso ao serviço de } \\
\text { interpretação e os profissionais de saúde não sabem trabalhar com um } \\
\text { intérprete de LS. } \\
\text { - Barreiras em relação ao acesso aos serviços psicossociais: há falta } \\
\text { de grupos de apoio para surdos/DA e de seus parentes vítimas de } \\
\text { trauma; há disponibilidade limitada de psicólogos especializados em } \\
\text { situações de trauma treinados para atender às pessoas surdas ou D.A. }\end{array}$ \\
\hline
\end{tabular}




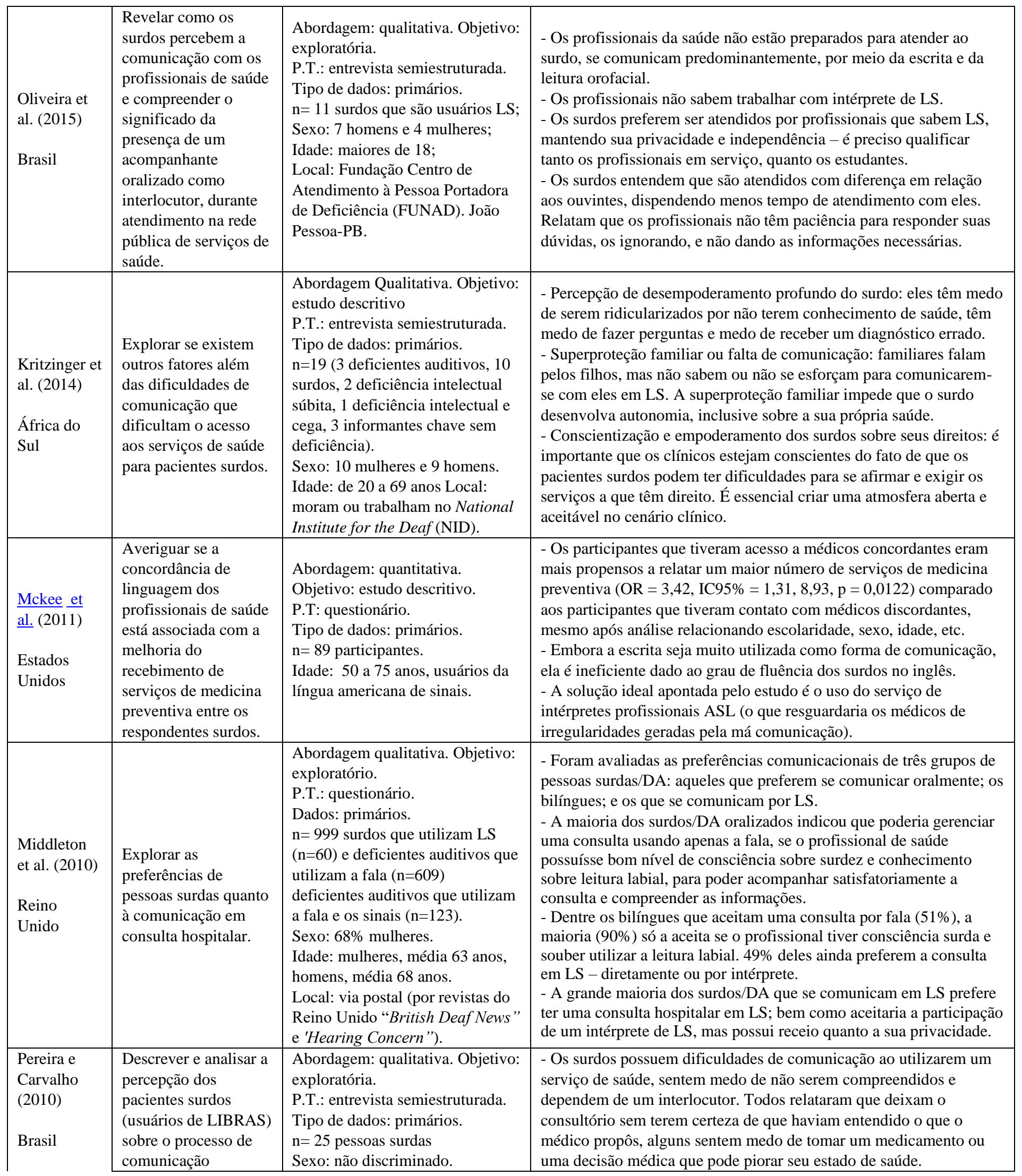




\begin{tabular}{|c|c|c|c|}
\hline $\begin{array}{l}\text { Freire et al. } \\
(2009) ; \\
\text { Brasil }\end{array}$ & $\begin{array}{l}\text { Comparar o acesso } \\
\text { das pessoas com } \\
\text { deficiência auditiva } \\
\text { incapacitante à } \\
\text { serviços assistenciais } \\
\text { e de prevenção com } \\
\text { os ouvintes de } \\
\text { Canoas, Rio Grande } \\
\text { do Sul, Brasil. }\end{array}$ & $\begin{array}{l}\text { Abordagem: quantitativo. } \\
\text { Estudo transversal, de base } \\
\text { populacional } \\
\text { P.T: questionário. } \\
\text { Tipo de dados: secundários. } \\
\text { n= } 1842 . \\
\text { Sexo:52\% mulheres. } \\
\text { Idade: maiores de } 15 \text { anos. } \\
\text { Local: banco de dados resultante } \\
\text { de uma pesquisa de base } \\
\text { populacional realizada na cidade } \\
\text { de Canoas, Rio Grande do Sul. }\end{array}$ & $\begin{array}{l}\text { - Os DA. apresentam } 30 \% \text { mais prevalência de } \mathrm{n}^{\circ} \text { de consultas do que } \\
\text { os ouvintes, o que pode indicar que seus problemas não têm sido } \\
\text { resolvidos de forma adequada. } \\
\text { - Os DA. tiveram } 40 \% \text { menos prevalência de usar preservativo na } \\
\text { última relação sexual do que os ouvintes; e as mulheres com } \\
\text { deficiência tiveram } 20 \% \text { menos prevalência de realizar autoexame } \\
\text { das mamas, assim como a média de anos decorridos desde o último } \\
\text { citopatológico de colo uterino das DA foi muito superior à das } \\
\text { ouvintes. } \\
\text {-Os dados da pesquisa reforçam a necessidade de investimentos em } \\
\text { campanhas específicas para DA para que estes tenham o mesmo } \\
\text { acesso aos serviços de saúde e medidas de prevenção que os } \\
\text { ouvintes. }\end{array}$ \\
\hline & $\begin{array}{l}\text { interpessoal e } \\
\text { informação na } \\
\text { assistência de saúde } \\
\text { úblice privada em São } \\
\text { Paulo, Brasil. }\end{array}$ & $\begin{array}{l}\text { Idade: maiores de } 18 . \\
\text { Local: São Paulo. }\end{array}$ & $\begin{array}{l}\text { - É rara a presença de intérpretes e há problemas quanto à sua } \\
\text { qualificação na área da saúde. A tradução realizada por } \\
\text { acompanhantes ou por intérpretes não qualificados pode trazer danos } \\
\text { iguais ou maiores do que quando não há tradução alguma. } \\
\text { - O choque cultural torna difícil manter tratamentos mais longos } \\
\text { (criar vínculo) e inviabiliza a troca de informações eficaz. Os } \\
\text { médicos não possuem conhecimento sobre a Cultura Surda, não } \\
\text { sabem trabalhar com intérpretes, e não possuem paciência para } \\
\text { encontrar alternativas de comunicação. }\end{array}$ \\
\hline
\end{tabular}

Quadro 1 - Acessibilidade aos Serviços de Saúde

Legenda: P.T: Procedimentos Técnicos; DA - deficientes auditivos; LS - Língua de Sinais; ASL - Língua Americana de Sinais.

\subsection{Acessibilidade em situações de emergências e catástrofes}

Esta categoria possui três artigos. Em dois deles, as autoras participam de ambas as publicações e são referências na área (IVEY et al., 2014; ENGELMAN et al., 2013). Estas pesquisas abordam a acessibilidade aos surdos/DA em situações de emergência e catástrofes - relativas à realidade encontrada nos Estados Unidos (terrorismo e desastres naturais, químicos ou nucleares). A discussão dos dois estudos gira em torno da preparação/treinamento dos profissionais e das organizações competentes para alertar e resgatar pessoas surdas/DA, uma vez que a comunicação é uma grande barreira nessas situações. Também foram realizadas avaliações quanto à qualidade desses serviços, e percebeu-se uma lacuna quanto ao treinamento e à preparação dos profissionais e organizações competentes na atenção à comunidade surda/DA em situações de emergência e de catástrofes. O terceiro estudo, realizado em Chipre, apresenta uma solução tecnológica 
para as pessoas surdas/DA em situações de emergência (CONSTANTINOU et al., 2017).

Trata-se de um aplicativo móvel que registra e envia os detalhes de um evento de emergência. $\mathrm{O}$ aplicativo possui interface e linguagem simples, composta por ícones que indicam o serviço a ser requisitado e dispensa uso de intermediários. Os resultados e dados específicos de cada pesquisa estão apresentados do Quadro 2.

\begin{tabular}{|c|c|c|c|}
\hline Autores & Objetivos & Método & Principais Resultados \\
\hline $\begin{array}{l}\text { Constantinou } \\
\text { et al. (2017) } \\
\text { Chipre }\end{array}$ & $\begin{array}{l}\text { Descrever uma } \\
\text { pesquisa-ação que } \\
\text { desenvolveu e avaliou } \\
\text { um sistema e visou } \\
\text { atender às } \\
\text { necessidades de } \\
\text { comunicação de } \\
\text { pessoas com DA em } \\
\text { casos de emergência. }\end{array}$ & $\begin{array}{l}\text { Abordagem: quali-quantitativa. } \\
\text { Objetivo: não informado. } \\
\text { P.T.: pesquisa-ação. } \\
\text { (questionários, grupos focais, } \\
\text { testes com usuário, entrevistas). } \\
\text { n= } 77 \text { ( } 61 \text { surdos; } 13 \text { DA; e } 3 \\
\text { policiais oficiais da polícia de } \\
\text { Chipre). Sexo: } 30 \text { mulheres e } 35 \\
\text { homens. Idade: média de } 42 . \\
\text { anos (de } 22 \text { a } 68 \text { anos). Local: } \\
\text { Chipre. }\end{array}$ & $\begin{array}{l}\text { - As avaliações demonstraram que o sistema é eficaz, obtendo } \\
\text { taxa de sucesso nos testes de } 100 \% \text {. } \\
\text { - É rápido (tempo médio de } 20 \text { a } 70 \text { s para solicitar serviço), } \\
\text { - Fácil de usar (ícones e linguagem simplificada); } \\
\text { - Pode ser utilizado com a infraestrutura já existente nos países } \\
\text { da União Europeia. } \\
\text { - O formato simples e com boa usabilidade do aplicativo torna } \\
\text { acessível o serviço de emergências para pessoas com as mais } \\
\text { diversas dificuldades de comunicação. }\end{array}$ \\
\hline
\end{tabular}

\begin{tabular}{|c|c|c|c|}
\hline$\frac{\text { Ivey et al. }}{(2014)}$ & $\begin{array}{l}\text { Averiguar se as } \\
\text { recomendações dos } \\
\text { Planos de Resposta a } \\
\text { Emergência em nível } \\
\text { estadual e territorial } \\
\text { (state- and territorial- } \\
\text { level emergency } \\
\text { operations plans - } \\
\text { EOPs) } \\
\text { para alertar os } \\
\text { surdos/DA em } \\
\text { situações de } \\
\text { catástrofes naturais } \\
\text { estão sendo aplicadas, } \\
\text { assim como o que os } \\
\text { estados estão fazendo } \\
\text { a respeito. }\end{array}$ & $\begin{array}{l}\text { Abordagem Quali-quantitativa } \\
\text { Objetivo: estudo descritivo } \\
\text { P.T.: Pesquisa participativa: } \\
\text { entrevista estruturada por } \\
\text { telefone. } \\
\text { Pesquisa documental: análise de } \\
50 \text { EOPs. } \\
\text { Tipo de dados: primários e } \\
\text { secundários. } \\
\mathrm{n}=55 \text { diretores. }\end{array}$ & $\begin{array}{l}\text { - Aspectos positivos: houve avanços em relação à análise } \\
\text { realizada em 2006, como a melhora no atendimento à } \\
\text { população surda/DA. Associação positiva do: aumento de } \\
\text { familiaridade dos KI em fazer chamadas por TTYs; e dos } \\
\text { departamentos em fornecerem treinamento para o atendimento } \\
\text { à população surda/DA. } \\
\text { - Constatou-se a importância das Comissões Estaduais para } \\
\text { Surdos (defesa de seus direitos) por meio da associação } \\
\text { significativa de sua presença e a adição, ou não, de novas } \\
\text { informações sobre comunicação e preparação dos surdos/DA } \\
\text { nos EOPs } \\
\text { Aspectos que podem ser melhorados: } 55 \% \text { dos (EOPs) têm um } \\
\text { plano para populações vulneráveis, mas apenas } 31 \% \\
\text { mencionaram planos para pessoas surdas/DA. } \\
\text { - São necessárias mais pesquisas sobre a preparação para } \\
\text { emergências para surdos/DA, incluindo o envolvimento desta } \\
\text { população na avaliação de suas necessidades, capacidades e } \\
\text { resistência em situações de emergência. } \\
\text { - É necessário melhorar o treinamento dos socorristas em } \\
\text { estados onde a concentração de surdos não é alta. }\end{array}$ \\
\hline $\begin{array}{l}\text { Engelman et } \\
\text { al. (2013) }\end{array}$ & $\begin{array}{l}\text { Avaliar o serviço de } \\
\text { atendimento aos } \\
\text { surdos oferecido pelo } \\
\text { State Emergency } \\
\text { Management } \\
\text { Agencies and Deaf- } \\
\text { serving Community- } \\
\text { based Organizations } \\
\text { (CBOs). Avaliar a } \\
\text { formação e o preparo } \\
\text { destas instituições } \\
\text { para situações de } \\
\text { emergência e } \\
\text { desastres naturais. }\end{array}$ & $\begin{array}{l}\text { Abordagem: qualitativa. } \\
\text { Objetivo: estudo descritivo. } \\
\text { P.T: } 1 \text {.Dados secundários de } \\
\text { entrevista com } 50 \text { KI de } \\
\text { agências públicas ou de gestão } \\
\text { (nível estadual ou territorial) } \\
\text { para avaliar informações de } \\
\text { prontidão para emergências e } \\
\text { capacidade de responder aos } \\
\text { Surdos/DA durante uma } \\
\text { emergência. E análise de } 50 \\
\text { planos básicos de operações de } \\
\text { emergência estaduais (EOPs). } \\
\text { 2. Entrevista com KI - deaf- } \\
\text { serving CBOs ( }=14 \text { ). } \\
\text { 3. Workshop com policiais } \\
\text { sobre conhecimento das leis } \\
\text { para surdos/DA seguido de pré- } \\
\text { teste ( } \mathrm{n}=34 \text { ) e dois grupos } \\
\text { focais ( } \mathrm{n}=6 \text { e } \mathrm{n}=13 \text { ). }\end{array}$ & $\begin{array}{l}\text { - As entrevistas com KI em CBOs locais apontaram que são } \\
\text { poucas CBOs que oferecem informações sobre preparação para } \\
\text { emergências a seus clientes surdos/DA, bem como são poucos } \\
\text { aqueles que oferecem treinamento específico para o } \\
\text { atendimento desta população. Recomenda-se: maior } \\
\text { acessibilidade e envolvimento dos Surdos/DA em treinamentos } \\
\text { e exercícios com orientação do pessoal do estado; treinamento } \\
\text { de competência cultural para os socorristas; diretrizes } \\
\text { padronizadas para as CBOs participarem do planejamento e } \\
\text { exercícios locais de emergência; desenvolvimento e } \\
\text { disseminação de diretrizes nacionais para o atendimento de } \\
\text { emergência da população surda/DA. } \\
\text { - O treinamento com os policiais teve impacto positivo, eles } \\
\text { desenvolveram habilidades de competência cultural e atitudinal } \\
\text { em relação ao público surdo, porém demonstraram falta de } \\
\text { conhecimento sobre as políticas federais e estaduais e sobre as } \\
\text { leis que asseguram o direito dos surdos/DA. }\end{array}$ \\
\hline
\end{tabular}


Quadro 2 - Acessibilidade em Situações de Emergências e Catástrofes

Legenda: P.T - procedimentos técnicos; DA - deficientes auditivos; KI - informantes chave; LS - Língua de Sinais; ASL - Língua Americana de Sinais; TYs - TeleTYpewriter.

\subsection{Acessibilidade no Sistema Judiciário}

Esta categoria possui quatro artigos, dois deles são relativos à mesma pesquisa realizada por Elder e Schwartz (2018) na Irlanda do Norte e abordam as implicações relacionadas à acessibilidade a pessoas surdas (usuárias de LS) ao contratar um advogado para ajudá-las a negociar eventos da vida - como financiar uma hipoteca, lidar com um divórcio, com um acidente de carro ou como preparar um testamento. A principal queixa foi em relação a uma barreira programática, onde a lei prevê que o prestador de serviços públicos forneça “ajustes razoáveis" para acessibilidade da pessoa surda; contudo, os advogados não se enquadram nesta lei, deixando toda a responsabilidade de contratação de um intérprete para o surdo. Já a pesquisa de Oslen et al. (2015), realizada na Noruega, aborda a acessibilidade nas várias áreas do sistema de justiça criminal, quando a pessoa surda é: vítima ou testemunha; suspeito ou condenado. Foram encontradas falta de competência em algumas áreas, especialmente em relação a tradução das terminologias judiciais para a LS pelos intérpretes. Estes nem sempre conhecem os termos jurídicos e, vários destes termos, não possuem tradução para LS; o mesmo ocorre com os surdos, nem todos eles compreendem estes termos, como consequência, tais fatores podem afetar o desenrolar dos processos. Corroborando com a pesquisa de Olsen, o estudo Brunson (2007) identificou que os intérpretes nem sempre conseguem ser neutros e traduzir literalmente o que o surdo ou o profissional falou, principalmente por causa do alcance do significado completo e das conotações que estão sendo traduzidas; pois os termos e as expressões ligadas à área jurídica são dotadas de conceitos; logo, os intérpretes devem ter conhecimento sobre a área. Além disso, Brunson identificou outras questões relacionadas à interação dos surdos com outros agentes da justiça. Esta e as demais informações sobre cada um dos artigos podem ser visualizadas no Quadro 3.

\begin{tabular}{|c|c|c|c|}
\hline Autores & Objetivos & Método & rincipais Resultados \\
\hline $\begin{array}{l}\text { Elder \& } \\
\text { Schwartz } \\
(2018) \\
\text { Reino Unido - } \\
\text { Irlanda do } \\
\text { Norte }\end{array}$ & $\begin{array}{l}\text { Explorar as experiências } \\
\text { pessoais de pessoas } \\
\text { surdas dentro do } \\
\text { sistema de justiça na } \\
\text { Irlanda do Norte para } \\
\text { entender melhor quais } \\
\text { fatores sociais podem } \\
\text { ter influenciado essas } \\
\text { experiências de vida. }\end{array}$ & $\begin{array}{l}\text { Abordagem Qualitativa. } \\
\text { Objetivo: exploratório. } \\
\text { Estudo etnográfico. } \\
\text { P.T.: entrevistas (intermédio } \\
\text { de intérprete de língua de } \\
\text { sinais). } \\
\text { Tipo de dados: primários. } \\
\text { n=8 surdos. } \\
\text { Idade: maiores de } 18 \text { anos. }\end{array}$ & $\begin{array}{l}\text { - Barreiras de acesso: os participantes dizem depender de alguém } \\
\text { da família, que muitas vezes nem sequer sinaliza, para } \\
\text { intermediar a comunicação, gerando frustração com a situação, } \\
\text { bem como podem ocorrer problemas graves em relação à } \\
\text { tradução incorreta dos termos. } \\
\text { - Ajuste razoável: a lei apenas recomenda que as instituições } \\
\text { públicas ofereçam “ajustes razoáveis" à população surda; muitos } \\
\text { profissionais entendem que a escrita no papel é um ajuste } \\
\text { razoável. }\end{array}$ \\
\hline
\end{tabular}




\begin{tabular}{|c|c|c|c|}
\hline & & Local: Irlanda do Norte. & $\begin{array}{l}\text { - Consciência sobre Cultural Surda: é muito importante haver, } \\
\text { tanto para surdos quanto para os integrantes do sistema de } \\
\text { justiça, um treinamento que englobe o atendimento à pessoa } \\
\text { surda e a consciência sobre a Cultura Surda e que sejam } \\
\text { desenvolvidos programas que possam alcançar resultados } \\
\text { efetivos. É comum que os treinamentos ofertados sobre pessoas } \\
\text { com deficiência priorizem apenas as deficiências visíveis; quase } \\
\text { nunca a surdez é citada. }\end{array}$ \\
\hline $\begin{array}{l}\text { Schwartz - } \\
\text { Elder (2018) } \\
\text { Reino Unido - } \\
\text { Irlanda do } \\
\text { Norte }\end{array}$ & $\begin{array}{l}\text { Explora as interações de } \\
\text { oito participantes surdos } \\
\text { em um sistema de } \\
\text { justiça na Irlanda do } \\
\text { Norte, }\end{array}$ & $\begin{array}{l}\text { Abordagem Qualitativa. } \\
\text { Objetivo: exploratório. } \\
\text { P.T.: entrevistas (intermédio } \\
\text { de intérprete de língua de } \\
\text { sinais). } \\
\text { Tipo de dados: primários. } \\
\text { n=8 surdos. } \\
\text { Idade: maiores de } 18 \text { anos. } \\
\text { Local: Irlanda do Norte. } \\
\text { Análise de dados: método } \\
\text { de comparação constante } \\
\text { (Charmaz e Mitchell 2001). }\end{array}$ & $\begin{array}{l}\text { - Barreiras: a principal barreira nos serviços de advocacia é o } \\
\text { custo do intérprete de LS. Os advogados interpretam o termo } \\
\text { "ajuste razoável" para evitar a contratação de um intérprete de } \\
\text { LS gerando custos que os surdos conseguem arcar. } \\
\text { - Barreira institucional: uma pessoa surda pode registrar uma } \\
\text { reclamação junto à Comissão de Igualdade (entidade do } \\
\text { governo da Irlanda do Norte encarregada da execução da lei), } \\
\text { mas o processo não é claro. Não há modificações na legislação } \\
\text { ou ações efetivas a partir dela, pois são poucos os surdos que } \\
\text { registram reclamações. Os participantes atribuem este problema } \\
\text { ao desconhecimento dos surdos em relação às leis e também o } \\
\text { acesso a tais informações legais, pois estas estão em linguagem } \\
\text { escrita; não há nada em LS. }\end{array}$ \\
\hline
\end{tabular}

\begin{tabular}{|c|c|c|c|}
\hline $\begin{array}{l}\text { Olsen et } \\
\text { al. (2015) } \\
\text { Noruega }\end{array}$ & $\begin{array}{l}\text { Como as pessoas surdas, } \\
\text { usuárias da língua de sinais } \\
\text { norueguesa (NSL), } \\
\text { experimentam as sessões do } \\
\text { sistema de justiça criminal } \\
\text { norueguês? E quais as } \\
\text { barreiras que as pessoas } \\
\text { surdas enfrentam ao } \\
\text { denunciar, ser acusado ou } \\
\text { ser testemunha de um crime } \\
\text { no tribunal? }\end{array}$ & $\begin{array}{l}\text { Abordagem: qualitativa. } \\
\text { Objetivo: não informado. } \\
\text { P.T.= entrevista } \\
\text { semiestruturada e aberta. } \\
\text { Tipo de dados: primários. } \\
\text { n= } 22 \text { ( } 7 \text { surdos; } 7 \\
\text { envolvidos na adm. de } \\
\text { direito penal; } 8 \text { intérpretes } \\
\text { LS). Obs.: os surdos já } \\
\text { haviam experimentado um } \\
\text { ou mais encontros com a } \\
\text { administração penal. }\end{array}$ & $\begin{array}{l}\text { - Vítima ou testemunha: os policiais não se preocupam em } \\
\text { acionar um intérprete na ocorrência, levando a má qualidade do } \\
\text { conteúdo no primeiro depoimento, e consequentemente levando } \\
\text { a diferenças substanciais no segundo depoimento - já com um } \\
\text { intérprete. } \\
\text { - Suspeito ou condenado: os policiais se preocupam quanto à } \\
\text { presença de um intérprete na primeira declaração, mas a } \\
\text { convocação é feita por telefone, o que é inacessível aos surdos. } \\
\text { Também é exigida a assinatura de sua declaração, que está } \\
\text { transcrita, e nem sempre os surdos compreendem tudo o que } \\
\text { está escrito, podendo comprometer o futuro de seu processo. } \\
\text { - Problemas quanto à tradução e interpretação. }\end{array}$ \\
\hline $\begin{array}{l}\text { Brunson } \\
(2007) \\
\text { Estados } \\
\text { Unidos }\end{array}$ & $\begin{array}{l}\text { Examinar como se dá a } \\
\text { negociação de acesso das } \\
\text { pessoas surdas durante as } \\
\text { interações com autoridades } \\
\text { legais. }\end{array}$ & $\begin{array}{l}\text { Abordagem: qualitativa. } \\
\text { Objetivo: exploratório. } \\
\text { P.T.: entrevista aberta (em } \\
\text { profundidade). } \\
\text { Tipo de dados: primários. } \\
\text { n= } 12 \text { pessoas surdas } \\
\text { Sexo: } 5 \text { mulheres e } 7 \\
\text { homens. } \\
\text { Idade: de } 20 \text { a } 60 \text { anos. } \\
\text { Local: duas cidades } \\
\text { metropolitanas no sudoeste } \\
\text { dos EUA. }\end{array}$ & $\begin{array}{l}\text { - Durante uma abordagem policial, muitas vezes, o policial não } \\
\text { conversa com o surdo e não chama um intérprete para que ele } \\
\text { possa relatar o "seu lado" durante uma ocorrência. Logo, o } \\
\text { policial fala com as pessoas envolvidas, com um conhecido da } \\
\text { pessoa surda, ou simplesmente não fala com ninguém ligado ao } \\
\text { surdo. Tais ações podem gerar uma penalidade injusta, que } \\
\text { pode prejudicar o surdo em sua pena, ou ter a penalidade } \\
\text { reduzida ou "anulada". } \\
\text { - Os participantes do estudo relataram que um bom intérprete } \\
\text { nem sempre é aquele que possui a certificação (RID). Eles } \\
\text { acham a certificação importante, mas o mais importante é que } \\
\text { ele esteja a par do caso, que mostre interesse e que possa } \\
\text { auxiliar o surdo de forma que este se sinta à vontade. } \\
\text { - Alguns surdos disseram que é comum acontecer de o } \\
\text { intérprete contratado pelo tribunal chegar atrasado, não } \\
\text { comparecer, ou até mesmo sair mais cedo da sessão. Pode } \\
\text { ocorrer, também, de o intérprete ultrapassar os limites de } \\
\text { neutralidade de sua função, atuando como assistente social "o } \\
\text { papel do intérprete é fornecer acesso e não conselho". }\end{array}$ \\
\hline
\end{tabular}

Quadro 3 - Acessibilidade no Sistema de Justiça

Legenda: P.T - procedimentos técnicos; RID: Registro de Intérpretes para Surdos

\subsection{Acessibilidade à cultura e ao lazer}

\section{Nesta categoria foram encontrados dois artigos sobre acessibilidade em museus por}


e, outro, acerca da acessibilidade a eventos culturais para pessoas com diferentes deficiências (MILLIGAN et al., 2014). Martins (2016) argumenta que as pessoas surdas ou com deficiência auditiva não apresentam bloqueios que as impeçam de conhecer e gostar de obras de arte, ressaltando que, por precisarem muito da visão para interagirem com o mundo, apresentam o que ele chama de uma forte "cultura visual". Ainda em relação à questão cultural, o trabalho evidencia que as informações precisam ser transmitidas não somente por meio de textos escritos na língua oral, já que aquelas pessoas fazem parte de uma minoria linguística e cultural e, sendo assim, será o intérprete que propiciará àquele público o acesso às obras de acordo com informações que façam sentido para elas. A presença do intérprete também reforçou o senso de pertencimento a uma comunidade e a afirmação da identidade e da Cultura Surda, pois tendo amplo conhecimento sobre a Comunidade Surda, o profissional sempre buscava vincular as obras de arte a períodos e fatos representativos para aquele grupo. Além disso, a visita guiada também se caracterizou como uma excelente oportunidade para o aprendizado de novos sinais e prática da LS, já que muitos participantes eram estudantes de LS. Por outro lado, a pesquisa de Goss et al. (2015), embora reconheça a importância da presença de intérpretes de LS, enfatiza a necessidade de utilização de outros recursos de acessibilidade, relembrando que entre as pessoas surdas ou com deficiência auditiva há indivíduos que se comunicam de diferentes formas, e não somente por meio da LS e, sendo assim, todos seriam beneficiados por meio da utilização de diferentes recursos que complementariam e facilitariam a comunicação e o acesso à informação por parte deste grupo.

Já o estudo de Milligan et al. (2014) demonstrou o desejo das pessoas com deficiência de participarem de eventos culturais e a frustração por serem privadas de tais atividades por falta de recursos de acessibilidade, já que gestores de organizações culturais, líderes políticos, entre outros, desconhecem a importância destes recursos; além disso, não encontram um local onde possam buscar informações sobre como essa acessibilidade deva ser realizada. A revisão de literatura ainda enfatizou os impactos positivos na saúde daqueles que participam de eventos culturais, como: redução de estresse, melhora no funcionamento físico e emocional e, consequentemente, maior sensação de bemestar. Outras informações sobre estas pesquisas encontram-se no quadro 4.

\begin{tabular}{|c|c|c|c|}
\hline Autores & Objetivo & Método & Resultados e Conclusões \\
\hline $\begin{array}{l}\text { Martins } \\
(2016) \\
\text { Portugal }\end{array}$ & $\begin{array}{l}\text { Como os museus poderiam } \\
\text { aumentar o engajamento do } \\
\text { público surdo? São as } \\
\text { barreiras para engajamento }\end{array}$ & $\begin{array}{l}\text { Abordagem: qualitativa. } \\
\text { Objetivo: exploratório. } \\
\text { P.T.: tour guiada. }\end{array}$ & $\begin{array}{l}\text { - Acessibilidade: é importante que a turnê seja guiada por uma pessoa } \\
\text { surda, ou então um intérprete de LS para garantir o acesso à informação } \\
\text { e a qualidade da experiência. } \\
\text { Benefícios da Tour em LS: }\end{array}$ \\
\hline
\end{tabular}




\begin{tabular}{|c|c|c|c|}
\hline & $\begin{array}{l}\text { cultural uma questão de } \\
\text { acesso e recursos? } \\
\text { Como a ausência da audição } \\
\text { pode afetar a experiência de } \\
\text { uma visita a um museu de } \\
\text { arte? } \\
\text { Quais os principais desafios } \\
\text { do museu relacionado ao } \\
\text { público surdo? }\end{array}$ & $\begin{array}{l}\text { Tipo de dados: } \\
\text { primários. } \\
\mathrm{n}=\mathrm{o} \text { autor não } \\
\text { especifica o número de } \\
\text { participantes (são } \\
\text { aproximadamente } 8 \\
\text { pessoas surdas). } \\
\text { Local: Museu Calouste } \\
\text { Gulbenkian em Lisboa } \\
\text { - Portugal. }\end{array}$ & $\begin{array}{l}\text { - Os museus têm o potencial de promover a educação dos surdos } \\
\text { quanto ao conteúdo da exposição, conhecimento sobre arte, e na } \\
\text { expansão do vocabulário de LS e termos relacionados à arte no sistema } \\
\text { de comunicação dos surdos. } \\
\text { - Promoção e apoio a perspectiva política da comunidade surda quanto } \\
\text { à sua identidade e à sua cultura. Também quanto à visibilidade e à } \\
\text { inclusão da comunidade surda. } \\
\text { - Sugestões: os museus podem oferecer atividades voltadas ao público } \\
\text { surdo (como conhecer a história dos surdos através dos artefatos ali } \\
\text { expostos). }\end{array}$ \\
\hline $\begin{array}{l}\text { Goss et al. } \\
(2015) \\
\text { Estados } \\
\text { Unidos }\end{array}$ & $\begin{array}{l}\text { Reconhecer as diferentes } \\
\text { possibilidades de } \\
\text { comunicação utilizadas } \\
\text { pelas pessoas surdas ou com } \\
\text { deficiência auditiva, que } \\
\text { não somente a utilização da } \\
\text { ASL, e pensar formas de } \\
\text { implementação destas novas } \\
\text { formas de comunicação. }\end{array}$ & $\begin{array}{l}\text { Abordagem: qualitativa. } \\
\text { Objetivo: exploratório. } \\
\text { P.T.: tour com } \\
\text { observação e entrevista } \\
\text { semiestruturada. } \\
\text { Tipo de dados: } \\
\text { primários. } \\
\text { n= } 600 \text { (15 grupos de } \\
\text { visitantes com } 40 \\
\text { participantes - não } \\
\text { especificam a situação } \\
\text { linguística dos } \\
\text { participantes). Local: } \\
\text { Museu de Ciência de } \\
\text { Boston - EUA. }\end{array}$ & $\begin{array}{l}\text { - Todos os participantes apresentaram situações em que suas } \\
\text { necessidades de comunicação não foram atendidas. Percebeu-se que o } \\
\text { museu está preparado para dar suporte apenas a um grupo de pessoas } \\
\text { surdas por vez - todo o suporte normalmente é baseado na presença de } \\
\text { um intérprete de ASL; } \\
\text { - Os grupos que utilizam LS e língua oral simultaneamente seriam } \\
\text { beneficiados com a utilização de outros recursos, como: gráficos, } \\
\text { textos, vídeos, etc. Mais pesquisas devem ser desenvolvidas neste } \\
\text { âmbito. } \\
\text { - Pessoas surdas/DA que se comunicam por meio da fala serão mais } \\
\text { bem assistidas se tiverem acesso a textos com informações simples e } \\
\text { diretas. } \\
\text { - Indivíduos de todos os grupos mencionaram que, em alguns } \\
\text { momentos, solicitam mais informações para os ouvintes que os } \\
\text { acompanham, ou seja, estão em situação de dependência para obter } \\
\text { informações - é necessário o desenvolvimento de soluções pontuais } \\
\text { para este problema. }\end{array}$ \\
\hline $\begin{array}{l}\text { Milligan } \\
\text { et al. } \\
(2014) \\
\text { Estados } \\
\text { Unidos }\end{array}$ & $\begin{array}{l}\text { Investigar maneiras de } \\
\text { melhorar a acessibilidade a } \\
\text { eventos culturais para } \\
\text { pessoas com deficiência em } \\
\text { uma cidade universitária do } \\
\text { Meio-Oeste dos Estados } \\
\text { Unidos. }\end{array}$ & $\begin{array}{l}\text { Abordagem: qualitativa } \\
\text { Objetivo: exploratório. } \\
\text { P.T.: grupos focais. } \\
\text { Tipo de dados: } \\
\text { primários. } \\
\text { n= } 39 \text { (13 participantes } \\
\text { com deficiência; } 8 \\
\text { gestores e organizações } \\
\text { culturais; } 9 \\
\text { cuidadores/profissionais } \\
\text { da saúde.; e } 9 \text { outros } \\
\text { interessados, como } \\
\text { líderes políticos). } \\
\text { Sexo: } 13 \text { homens e } 26 \\
\text { mulheres. } \\
\text { Idade: de } 18 \text { a } 84 \text { anos. }\end{array}$ & $\begin{array}{l}\text { - As pessoas com deficiência querem participar de eventos culturais, } \\
\text { mas não existe acesso. No caso dos surdos, a inexistência de acesso se } \\
\text { dá por não existir tradução para Libras durante os eventos e também } \\
\text { em suas divulgações; } \\
\text { - Existe um conhecimento limitado sobre acessibilidade entre as } \\
\text { pessoas com deficiência e falta de conscientização sobre o mesmo tema } \\
\text { por parte dos gestores e organizações culturais; } \\
\text { - Há a necessidade de criar uma central para alimentar e compartilhar } \\
\text { essas informações, assim como existe a necessidade de criar políticas } \\
\text { públicas para a inclusão das pessoas com deficiência nos eventos } \\
\text { culturais. }\end{array}$ \\
\hline
\end{tabular}

Quadro 4 - Acessibilidade aos Serviços de Cultura e Lazer

Legenda: P.T - procedimentos técnicos; DA - deficientes auditivos; ASL - Língua Americana de Sinais

\section{Discussão}

Os resultados demonstraram que, independentemente do país, ou do tipo de serviço, todos eles apresentam barreiras no acesso e utilização destes pelo público surdo/DA. As barreiras comunicacionais e atitudinais possuem maior ocorrência dentre as pesquisas. As consequências das barreiras de acessibilidade impactam na qualidade do serviço entregue, assim como na autonomia, na dignidade e na segurança da pessoa surda/DA. Os resultados foram discutidos a partir das dimensões de barreiras estabelecidas por Sassaki (2006). 
Foram identificadas três dimensões: barreiras comunicacionais, atitudinais e programáticas.

\subsection{Barreiras Comunicacionais}

As barreiras comunicacionais são o principal empecilho para que o atendimento a pessoa surda/DA ocorra com segurança e qualidade. Para que a população surda/DA receba um atendimento equitativo, é preciso que os profissionais e organizações estejam preparados para atendê-los. É necessário conhecer as diferenças dentro do universo da surdez para que seja utilizado o recurso de comunicação mais adequado e da preferência do cliente.

Os resultados evidenciaram que é baixo o nível de preparação dos profissionais e organizações a respeito das características, limitações e necessidades da população surda/DA. É ínfimo o número de profissionais que receberam algum tipo de capacitação para atender, especialmente, a população surda pré-lingual. Apenas a pesquisa de Engelman et al. (2013) apontou que os profissionais de emergência haviam recebido um curso de competência cultural, o qual trouxe resultados positivos. Também são raros os serviços que oferecem intérpretes de língua de sinais em todas as áreas aqui listadas.

Os erros mais recorrentes dos profissionais estão associados à crença de que todos os surdos/DA compreendem perfeitamente a linguagem escrita ou sabem fazer leitura orofacial. Alguns utilizam estes recursos, pois não têm conhecimento, ou não sabem como solicitar um intérprete de LS, outros acreditam que este não é necessário, e, simplesmente, tomam essa decisão pelo surdo. Nem todos os surdos dominam a leitura, a escrita e a leitura orofacial, todos esses recursos dependem do grau de alfabetização do indivíduo (CROWE, 2017; BARNETT, 2002). Garberoglio et al. (2014) explica que há uma vasta literatura sobre a alfabetização de pessoas surdas e que é recorrente a compreensão de que os surdos estão constantemente "enfrentando desafios" ou "lutando com a alfabetização". Oliveira (2015) ressalta que, mesmo os surdos com Ensino Superior, enfrentam dificuldades em compreender a língua portuguesa. A escrita, no entanto, pode ser útil para a comunicação de sentenças curtas, como ocorre quando é necessário agendar uma consulta médica (CROWE, 2017).

A comunicação ideal para os surdos pré-linguais, ou aqueles que se identificam com a Cultura Surda, é a língua de sinais (STROBEL, 2009; BARNETT, 2002). Se o profissional não tiver esse conhecimento, é necessário solicitar um intérprete profissional para realizar a mediação. Quando não há profissionais qualificados e intérpretes de língua de sinais, o surdo 
passa a depender de sua família e conhecidos para acessar os serviços. Nem sempre essas pessoas estarão disponíveis ou terão conhecimento suficiente de LS para realizar a mediação; por conseguinte, a pessoa surda/DA pode deixar de acessar o serviço, receber um atendimento de baixa qualidade ou receber informações incompletas (CARDOSO, 2006). Tais situações contribuem para o alienamento e exclusão social desta população.

\subsection{Barreiras Programáticas}

As barreiras encontradas nas leis e regulamentações estão relacionadas à escolha do recurso de comunicação adequado. A maior parte das situações ocorre no sistema de justiça e serviços de saúde. A principal barreira programática diz respeito à concessão de "ajustes razoáveis" às pessoas surdas/DA, para utilizar, com acessibilidade, um serviço público ou de uso público. Esta barreira foi identificada em 3 pesquisas - duas delas foram aplicadas na Irlanda do Norte (ELDER; SCHWARTZ, 2018)e a outra nos Estados Unidos (BRUNSON, 2007). Tanto o "Discrimination Disabilities Act" (DDA), na Irlanda do Norte, quanto o "The Americans with Disabilities Act", nos Estados Unidos, recomendam que as instituições públicas ofereçam “ajustes razoáveis” à população surda. No entanto, é o prestador de serviço que determina qual recurso será utilizado, e, ao contrário do que os surdos relataram ter convicção, eles não têm direito garantido a um intérprete de LS. Desta forma, "ficam à mercê" do que o prestador de serviços considerar adequado (BRUSON, 2007). É comum que o prestador, por uma questão de custos, entenda que a escrita e a leitura orofacial são “ajustes razoáveis". Contudo, a utilização desses recursos não é suficiente para troca de informações complexas. Um dos participantes, ao se comunicar por escrita com seu advogado, disse ter perdido cerca de 70\% do que foi dito (ELDER; SCHWARTZ, 2018). No estudo de Santos e Portes (2019), 70\% das pessoas surdas dizem não compreender as orientações sobre seu tratamento a partir das estratégias de comunicação, como a escrita e a leitura labial. A ausência de um intérprete de LS, especialmente em contextos que englobam questões jurídicas complexas (abordagem policial, sessões dos tribunais), pode comprometer o desenrolar do processo e a segurança e fidedignidade das informações compartilhadas (SCHWARTZ; ELDER, 2018). O mesmo ocorre nos serviços de saúde - os prestadores podem interpretar a lei conforme seu entendimento, gerando possibilidade de erro no diagnóstico e tratamento do paciente (PENDERGRASS et al., 2017).

Esta questão é ainda mais problemática nos serviços prestados por advogados, pois ao contrário dos tribunais e da polícia, as empresas de advocacia são serviços privados que 
não estão sujeitos à lei; portanto, utilizam tal argumento para não pagar pelo intérprete. $\mathrm{Na}$ Irlanda no Norte e nos Estados Unidos, por exemplo, se o surdo não possuir renda muito baixa, não conseguirá suporte financeiro do governo e terá que pagar o intérprete, ou terá sua apólice de seguro aumentada - mesmo não tendo condições financeiras para tanto (ELDER; SCHWARTZ, 2018; SCHWARTZ; ELDER, 2018). Muitos surdos relataram sua frustração em relação à abertura que a lei traz para a intepretação do que é “ajuste razoável”, e que vem ao encontro da tendência histórica de pessoas ouvintes decidirem o que é melhor para as pessoas surdas quanto à acessibilidade. Para eles, tal ação contrasta intensamente com o enfoque centrado no indivíduo - que é fundamental para criar acesso equitativo à justiça para pessoas com deficiências (ELDER; SCHWARTZ, 2018).

\subsection{Barreiras Atitudinais}

O contexto dos surdos/DA, ainda hoje, é envolto em estereótipos e mitos que levam ao preconceito e ao estigma. De acordo com Rinehart (1963), estereótipos são conjuntos de crenças, geralmente declaradas como generalizações categóricas, que as pessoas sustentam sobre os membros de seus próprios grupos, e de outros grupos, que raramente refletem a realidade. Crowe (2017) acredita que os estereótipos são mais do que isso, são estruturas cognitivas que influenciam as percepções, a atenção e a memória, e podem levar ao preconceito - consciente ou inconsciente. Alguns exemplos comuns de estereótipos sobre a pessoa surda são: chamá-los de surdo-mudo, que é um termo com o qual eles não se identificam, visto que seu aparelho fonador funciona normalmente; falar bem alto para que o surdo compreenda o que está sendo dito - eles não vão "ouvir"; acreditar que a comunicação gestual é apenas mímica, e acreditar que eles possuem alguma deficiência mental ou intelectual (GESSER, 2009).

Crowe (2017) adverte que o preconceito, inconsciente ou consciente, em relação a um cliente (no caso da autora, paciente) pode afetar negativamente o relacionamento de várias maneiras. Para fornecer serviços cultural e linguisticamente sensíveis, os profissionais devem estar cientes dos mitos comumente sustentados, para que não interfiram em seu atendimento e relacionamento com o cliente. Em seu artigo, Crowe (2017) descreve 10 mitos sobre as pessoas surdas que são comuns na sociedade: 1. a Cultura Surda não existe; 2. pessoas surdas gostam de ser chamadas de deficientes auditivos; 3 . todas as pessoas surdas usam linguagem de sinais; 4. todas as pessoas surdas podem ler os lábios; 5. escrever para uma pessoa surda é tão bom quanto usar um letreiro luminoso; 6. pessoas surdas querem ter 
uma cura milagrosa para se tornarem ouvintes; 7. aparelhos auditivos e implantes cocleares podem fazer todas as pessoas surdas ouvirem normalmente; 8. pessoas surdas são menos inteligentes do que pessoas que ouvem; 9. qualquer pessoa que sinalize pode ser intérprete; e 10. quanto mais surda uma pessoa, maior a chance de doença mental.

Os relatos encontrados nesta revisão evidenciaram alguns exemplos de barreiras atitudinais e mitos que englobam, principalmente, ações de discriminação e preconceito. Um exemplo recorrente nos serviços de justiça é relativo à consequência da falta de um intérprete ou um acompanhante durante uma ocorrência (seja o surdo vítima ou culpado), onde a pessoa surda é tratada de forma diferente das demais, sendo beneficiada ou penalizada injustamente. Um exemplo da primeira situação é descrito na pesquisa de Brunson (2007), onde há relatos de que policiais reduzem o valor das multas para os surdos por saberem que não poderão oferecer recursos de acessibilidade, ou por não terem paciência de seguir todos os procedimentos necessários para aquela determinada situação. Na segunda situação, um dos exemplos é o de uma mulher surda que se envolveu em um acidente de trânsito e não teve seu depoimento coletado pelo policial; em consequência disso, ela foi considerada culpada e, além da multa, teve sua apólice de seguro aumentada. Posteriormente, ela lutou por dois anos no tribunal para ser absolvida e ressarcida (BRUNSON, 2007).

Situações de discriminação também foram relatadas em três estudos da área da saúde. Os surdos percebem que os profissionais não têm paciência para atendê-los, ficam irritados e não respondem às informações requisitadas. Além disso, eles acreditam que os profissionais gastam menos tempo com eles do que com pessoas ouvintes (SKØT, 2016; OLIVEIRA et al., 2015; PEREIRA; CARVALHO, 2010). Outra situação recorrente ocorre quando os profissionais de saúde, ou do sistema de justiça, conversam com o intérprete ou com o acompanhante ao invés de conversar com a pessoa surda, impedindo ou anulando sua participação no atendimento (SANTOS.PORTES, 2019; SIRCH et al., 2016; OLIVEIRA ET AL., 2015; BRUNSON, 2007). Ao longo deste artigo também foram apresentados exemplos relacionados aos mitos 4, 5 e 9. Crowe (2017) argumenta que as pessoas podem ter essas crenças devido à pouca exposição a indivíduos surdos, ou podem acreditar nelas por meio de retratos da mídia, incluindo livros, filmes e programas de televisão. Podem ainda ter ideias erradas por causa de experiências anedóticas ou do que outros lhes contaram (CROWE, 2017). 


\section{Considerações Finais}

Constatou-se que, independentemente do país, ou do tipo de serviço (saúde, emergência, justiça ou cultura), todos os estudos apontaram a existência de barreiras comunicacionais e atitudinais, como: falta de conscientização das organizações a respeito das necessidades e singularidades do público surdo; falta de protocolos para o atendimento desta população, sobretudo nos serviços de justiça e saúde; rara presença de intérpretes de língua de sinais ou profissionais capacitados para atender este público em LS. Outra barreira identificada em alguns estudos do setor de justiça e de saúde foi a programática; tais estudos evidenciaram que as leis referentes à escolha do recurso de comunicação a ser utilizado no serviço para a comunicação com a pessoa surda não é escolhido pelo surdo, mas pelo provedor do serviço - conforme ele achar adequado. Com a ausência de recursos de comunicação no setor de serviços, os surdos se deparam com três situações: (1) necessitam do auxílio de um familiar ou conhecido e assim perdem sua autonomia; (2) utilizam a escrita, ou a leitura orofacial como alternativa de comunicação - linguagens estas que nem todos os surdos têm domínio ou facilidade - podendo interferir na fidedignidade das informações e, consequentemente, na sua própria segurança e saúde; (3) evitam ou desistem de acessar o serviço.

\subsection{Limitações da Pesquisa}

Os descritores utilizados para fazer as buscas nas bases de dados são abrangentes, pois era necessário captar o maior número de áreas possível. Por conseguinte, artigos mais específicos de cada área não foram alcançados. Sugere-se para futuras pesquisas a busca em cada área por meio de descritores específicos. Outra limitação é relativa à exclusão de artigos que não estavam disponíveis para download. Logo, é sabido que há diversos artigos, especialmente na área de emergência, com resultados ainda mais recentes.

\section{Referências}

AZEREDO, Eduardo. Língua de Sinais: uma conquista histórica. Brasília - DF: Secretaria Especial de Editoração e Publicações - Senado Federal (Os:nº 03747), 2006.

BARDIN, Laurence. Análise de conteúdo. Lisboa: Edições 70, 1977. 
BARNETT, Steven. Communication with deaf and hard-of-hearing people: a guide for medical education. Academic Medicine, v. 77, n. 7, p. 694-700, 2002.

BOTELHO, Louise Lira Roedel; DE ALMEIDA CUNHA, Cristiano Castro; MACEDO, Marcelo. O método da revisão integrativa nos estudos organizacionais. Gestão e sociedade, v. 5, n. 11, p. 121-136, 2011. https://doi.org/10.21171/ges.v5i11.1220

BRASIL. Lei no 13.146, de 6 de julho de 2015. Institui a Lei Brasileira de Inclusão da Pessoa com Deficiência (Estatuto da Pessoa com Deficiência). Diário Oficial [da] República Federativa do Brasil, Brasília, DF, 2015. Disponível em: https://www2.camara.leg.br/legin/fed/lei/2015/lei-13146-6-julho-2015-781174normaatualizada-pl.html Acessado em setembro de 2020.

BRASIL. Lei n ${ }^{\circ} 10.436$, de 24 de abril de 2002. Dispõe sobre a Língua de Sinais - Libras e dá outras providências. Diário Oficial [da] República Federativa do Brasil, Brasília, DF. 24 abr. 2002. Disponível em: <http://www.planalto.gov.br/ccivil_03/_ato20042006/2005/decreto/d5626.htm>. Acessado em julho de 2020.

BRASIL. Decreto $n^{0} 5.296$, de 2 de dez. de 2004. Regulamenta as Leis $\mathrm{n}^{\mathrm{os}} 10.048$, de 8 de nov. de 2000, que dá prioridade de atendimento às pessoas que especifica, e 10.098, de 19 de dez. de 2000, que estabelece normas gerais e critérios básicos para a promoção da acessibilidade das pessoas portadoras de deficiência ou com mobilidade reduzida. Diário Oficial [da] República Federativa do Brasil, Brasília, DF, 2004. Disponível em <http://www.planalto.gov.br/ccivil_03/_ato2004-2006/2004/Decreto/D5296.htm> Acessado em julho de 2020.

BRUNSON, Jeremy L. Your case will now be heard: Sign language interpreters as problematic accommodations in legal interactions. Journal of deaf studies and deaf education, v. 13, n. 1, p. 77-91, 2007.Carvalho, P. V (2013). A herança do Abade de L'Épée na viragem do século XVIII para o século XIX. Lisboa: The Factory. https://doi.org/10.1093/deafed/enm032 
CARDOSO, Adriane Helena Alves; RODRIGUES, Karla Gomes; BACHION, Maria Márcia. Perception of persons with severe or profound deafness about the communication process during health care. Revista latino-americana de enfermagem, v. 14, n. 4, p. 553 560, 2006. https://doi.org/10.1590/S0104-11692006000400013

CHAVEIRO, Neuma; BARBOSA, Maria Alves; PORTO, Celmo Celeno. Revisão de literatura sobre o atendimento ao paciente surdo pelos profissionais da saúde. Revista da Escola de Enfermagem da USP, v. 42, n. 3, p. 578-583, 2008. https://doi.org/10.1590/S0080-62342008000300023

CONSTANTINOU, Vaso; IOANNOU, Andri; DIAZ, Paloma. Inclusive access to emergency services: an action research project focused on hearing-impaired citizens. Universal access in the information society, v. 16, n. 4, p. 929-937, 2017. https://doi.org/10.1007/s10209-016-0509-5

CROWE, Teresa. You're Deaf? Breaking through myths for effective therapeutic practice. Journal of Social Work in Disability \& Rehabilitation, v. 16, n. 3-4, p. 230-246, 2017. https://doi.org/10.1080/1536710X.2017.1372239

ELDER, Brent C.; SCHWARTZ, Michael A. Effective deaf access to justice. The Journal of Deaf Studies and Deaf Education, v. 23, n. 4, p. 331-340, 2018. https://doi.org/10.1093/deafed/eny023

ENGELMAN, Alina et al. Responding to the deaf in disasters: establishing the need for systematic training for state-level emergency management agencies and community organizations. BMC health services research, v. 13, n. 1, p. 84, 2013. https://doi.org/10.1186/1472-6963-13-84

FREIRE, Daniela Buchrieser et al. Acesso de pessoas deficientes auditivas a serviços de saúde em cidade do Sul do Brasil. Cadernos de Saúde Pública, v. 25, p. 889-897, 2009. https://doi.org/10.1089/15409990260363689

GESSER, Audrei. LIBRAS? que língua é essa? São Paulo: Parábola, 2009. 
GOSS, Juli et al. Understanding the multilingualism and communication of museum visitors who are d/Deaf or hard of hearing. Museums \& Social Issues, v. 10, n. 1, p. 52-65, 2015. https://doi.org/10.1179/1559689314Z.00000000032

INSTITUTO BRASILEIRO DE GEOGRAFIA E ESTATÍSTICA - IBGE (Cartógrafo). (2010). Dados demográficos pessoas com deficiência. Disponível em: $<$ https://www.gov.br/mdh/pt-br/navegue-por-temas/pessoa-comdeficiencia/app/sites/default/files/publicacoes/cartilha-censo-2010-pessoas-comdeficienciareduzido.pdf > Acessado em setembro de 2020.

IVEY, Susan L. et al. Assessment of state-and territorial-level preparedness capacity for serving deaf and hard-of-hearing populations in disasters. Public Health Reports, v. 129, n. 2, p. 148-155, 2014. https://doi.org/10.1177/003335491412900208

KRITZINGER, Janis et al. "I just answer 'yes' to everything they say": Access to health care for deaf people in Worcester, South Africa and the politics of exclusion. Patient education and counseling, v. 94, n. 3, p. 379-383, 2014. https://doi.org/10.1016/j.pec.2013.12.006

MARTINS, Patrícia Roque. Engaging the d/Deaf Audience in Museums: A Case Study at the Calouste Gulbenkian Museum. Journal of Museum Education, v. 41, n. 3, p. 202-209, 2016. https://doi.org/10.1080/10598650.2016.1193316

MCKEE, Michael M. et al. Impact of communication on preventive services among deaf American Sign Language users. American journal of preventive medicine, v. 41, n. 1, p. 75-79, 2011. https://doi.org/10.1016/j.amepre.2011.03.004

MIDDLETON, Anna et al. Preferences for communication in clinic from deaf people: A cross-sectional study. Journal of Evaluation in Clinical Practice, v. 16, n. 4, p. 811-817, 2010. https://doi.org/10.1111/j.1365-2753.2009.01207.x

MILLIGAN, Nancy Vandewiele; NIEUWENHUIJSEN, Els R.; GRAWI, Carolyn L. Using a participatory action strategic approach to enhance accessibility and participation in arts 
and cultural events: Results of four focus groups. Disability and health journal, v. 7, n. 1, p. 105-113, 2014. https://doi.org/10.1016/j.dhjo.2013.09.001

MONT, O. Product service-system. Swedish Environmental Protection Agency, Sweden, 2000 .

OLIVEIRA, Yanik Carla Araújo de; CELINO, Suely Deysny de Matos; COSTA, Gabriela Maria Cavalcanti. Communication as an essential tool for deaf people's health care. Physis: Revista de Saúde Coletiva, v. 25, n. 1, p. 307-320, 2015. https://doi.org/10.1590/S0103$\underline{73312015000100017}$

OLSEN, Terje; KERMIT, Patrick. Sign language, translation and rule of law-deaf people's experiences from encounters with the Norwegian criminal justice system. Scandinavian Journal of Disability Research, v. 17, n. sup1, p. 23-41, 2015. https://doi.org/10.1080/15017419.2014.972448

PALADINI, E. P. Gestão da qualidade: teoria e casos. Rio de Janeiro: Elsevier, 2005.

PENDERGRASS, Kathy M. et al. Nurse practitioner perceptions of barriers and facilitators in providing health care for deaf American Sign Language users: A qualitative socioecological approach. Journal of the American Association of Nurse Practitioners, v. 29, n. 6, p. 316-323, 2017. https://doi.org/10.1002/2327-6924.12461

PEREIRA, Patrícia Cristina Andrade; DE CARVALHO FORTES, Paulo Antonio. Communication and information barriers to health assistance for deaf patients. American annals of the deaf, $\quad$ v. 155, n. 1, p. 31-37, 2010. Disponível em: <https://www.jstor.org/stable/26235016?seq=1 > Acessado em outubro de 2020.

RINEHART, James W. The meaning of stereotypes. Theory into Practice, v. 2, n. 3, p. 136-143, 1963. https://doi.org/10.1080/00405846309541852 
SANTOS, Alane Santana; PORTES, Arlindo José Freire. Perceptions of deaf subjects about communication in Primary Health Care. Rev. Latino-Am. Enfermagem, Ribeirão Preto , v. 27, e3127, 2019. https://doi.org/10.1590/1518-8345.2612.3127

SASSAKI, Romeu Kazumi. Inclusão: construindo uma sociedade para todos. 7. ed. Rio de Janeiro: WVA, 2006.

SCHWARTZ, Michael A.; ELDER, Brent C. Deaf access to justice in Northern Ireland: rethinking 'Reasonable Adjustment'in the Disability Discrimination Act. Disability \& Society, v. 33, n. 7, p. 1003-1024, 2018. https://doi.org/10.1080/09687599.2018.1478801

SILVESTRO, Rhian. Positioning services along the volume-variety diagonal: the contingencies of service design, control and improvement. International Journal of Operations \& Production Management, v. 19, n. 4, p. 399-421, 1999. https://doi.org/10.1108/01443579910254268

SIRCH, Linda; SALVADOR, Linda; PALESE, Alvisa. Communication difficulties experienced by deaf male patients during their in-hospital stay: findings from a qualitative descriptive study. Scandinavian journal of caring sciences, v. 31, n. 2, p. 368-377, 2017. https://doi.org/10.1111/scs.12356

SKØT, Lotte et al. Accessibility of medical and psychosocial services following disasters and other traumatic events: Experiences of deaf and hard-of-hearing individuals in Denmark. Disability and rehabilitation, v. 39, n. 24, p. 2468-2476, 2017. https://doi.org/10.1080/09638288.2016.1236154

STROBEL, K. As imagens do outro sobre a cultura surda. 2. ed. rev. Florianópolis: Editora da UFSC, 2009.

UNITED NATIONS. Accessibility and Development: mainstreaming disability in the post2015 development agenda. Disponível em: 
<https://www.un.org/development/desa/dspd/2013/12/accessibility-and-developmentmainstreaming-disability-in-the-post-2015-development-agenda/> Acessado em setembro de 2020.

WHITTEMORE, Robin; KNAFL, Kathleen. The integrative review: updated methodology. Journal of advanced nursing, v. 52, n. 5, p. 546-553, 2005. https://doi.org/10.1111/j.1365-2648.2005.03621.x 